\title{
Risk Analysis and Strong Ground Motion Characteristics of Ludian Ms 6.5 Earthquake
}

Sen Qiao, Xueliang Chen, Aiwen Liu, Zengping Wen, Xiaojun Li, Zongchao Li, Tiefei Li

Institute of Geophysics, China Earthquake Administration, Beijing 100081, China

\section{鲁甸 Ms6.5 地震的强地面运动研究及灾害风险 分析}

乔森, 陈学良, 刘爱文, 温增平, 李小军, 李宗超, 李铁飞

中国地震局地球物理研究所, 北京 100081 , 中国

\begin{abstract}
There was an earthquake hit Ludian county, Yunnan province on August 3, 2014, and the seismogenic fault was the North-West Baogunao-Xiaohe Fault. The magnitude of the surface wave magnitude (Ms) was 6.5 , not so large, but the earthquake caused severe casualties. The main-shock strong ground motions were recorded by 7 observation stations. Longtoushan Finance Office station located in the epicenter area perfectly recorded throughout the whole event, and the PGA of this record in EW direction is $948.5 \mathrm{~cm} / \mathrm{s}^{2}$, which is nearly $1 \mathrm{~g}$ $\left(981 \mathrm{~cm} / \mathrm{s}^{2}\right)$. The horizontal component of ground motion observation records are decomposed and synthesized in accordance with the direction of parallel to the seismogenic fault and the direction of perpendicular to the seismogenic fault. Analysis results showed that the attenuation of PGA(peak ground acceleration) in NW-SE direction is slower than that in NE-SW direction. The intensity recorded by the strong ground motion was basically in accordance with the severity of earthquake disaster in the around area.
\end{abstract}

Keywords: Ludian earthquake; Strong ground motion; Disaster characteristic; Risk analysis

\begin{abstract}
摘要: 2014 年 8 月 3 日云南鲁甸发生了一次中强 地震, 发震断层为北西向的包谷垴-小河断裂。此 次地震的面波震级 $\left(M_{s}\right)$ 为 6.5 , 震级不大却造成 了严重的人员伤亡和经济损失。灾区的 7 个强震台 站获得了此次地震的加速度记录, 其中, 位于极震 区鲁甸龙头山镇财政所强震记录, 其东西向 PGA 达到 $948.5 \mathrm{~cm} / \mathrm{s}^{2}$ 。本文对鲁甸 Ms6.5 地震动观测 记录按照平行于发震断层方向和垂直于发震断层 方向进行分析, 结果表明峰值加速度的分布沿北西 -东南 (NW-SE) 方向衰减较慢, 而沿北东-南西 (NE-SW) 方向衰减相对较快。强震台所记录到的地 震动强度与该地区的灾害严重程度基本符合。
\end{abstract}

关键词: 鲁甸地震, 强地震动, 灾害特征, 风险 分析;

1. 引言

2014 年 8 月 3 日 16 时 30 分云南省昭通市鲁 甸县发生了一次中强地震, 却造成了严重的地震灾 害损失, 地震应急响应达到我国最高的一级响应。 中国地震台网中心确定的地震面波震级 $\left(M_{S}\right)$ 为 6.5, 美国 USGS 给定的矩震级 $\left(M_{w}\right)$ 为 6.1 。地震 的震中位置位于鲁甸县的龙头山镇附近 $\left(27.1^{\circ} \mathrm{N}\right.$, $103.3^{\circ} \mathrm{E}$ ), 震源深度为 $12 \mathrm{~km}$ 。根据地震现场调查, 云南省灾区亡 617 人死、失踪 112 人, 3143 人受 伤, 极震区烈度达到 IX 度, 龙头山镇房屋倒塌严 
重, 包括抗震能力相对较好的框架结构 ${ }^{[1]}$ 。

昭通市位于云南省东北部边缘与四川交界处, 是云南省 7 大地震带之一, 属于地震多发地区。昭 通地区地处云贵高原的乌蒙山区, 境内地势起伏较 大, 地形险峻、山势徒峭、重峦叠嶂、沟韰纵横。 由于该地区经济相对落后, 民居抗震能力较低而人 口密度又较大, 因此该地区一直是云南省地震灾害 风险较高的地区。近些年来已经发生多次灾难性地 震。2004 年 8 月 10 日, 昭通市昭阳区、鲁甸县交 界处发生 5.6 级地震, 导致 4 人死亡, 594 人受伤; 2006 年 7 月 22 日, 昭通市盐津县发生 Ms 5.1 级地 震, 造成 22 人死亡, 百余人受伤。 2012 年 9 月 7 日昭通市杽良县发生 5.7 级地震, 当日 12 时 16 分, 又发生 5.6 级地震, 造成 81 人死亡, 821 人受伤。 通过对云南鲁甸 6.5 级地震震害开展实地调 查, 对各烈度区特征和建筑物震害、地震地质灾害、 工程结构震害的分析, 帅向华, 姜立新等 ${ }^{[2]}$ 初步得 $^{\circ}$ 出本次地震的一些震害特点: 一是灾区人口密度大, 人员死亡较集中。人员死亡主要集中在VIII和IX度区。 二是地震震动强, 灾区破坏严重。本次地震震源深 度 $12 \mathrm{~km}$, 极震区烈度高达IX度, 震源破裂在 $11 \mathrm{~s}$ 内集中释放。三是抗震能力弱, 房屋破坏严重。灾 区属国家级贫困区, 农村民居抗震能力弱, 且多数 民房坐落在河谷陡坡上, 边坡效应加重房屋震害, 重灾区砖木和土木房屋成片损毁、倒塌。

在此次鲁甸地震中, 共有 80 个强震台站被触 发, 其中震中附近的龙头山镇台站获得了峰值加速 度超过 900gal 的强震记录 ${ }^{[3,4]}$ 。这次地震中烈度为 VI度及以上区域共 7 个强震动台站, 本文对这 7 个台站的强震动主震记录进行了处理, 将水平向的 地震动分解为平行于发震断层方向分量和垂直于 发震断层方向分量, 得出了两个新的水平分量的地 震动时程图, 以及相应的反应谱图和傅里叶谱图, 分析了地震动沿平行断层方向以及垂直断层方向 的基本特征, 从幅值特征、衰减关系等方面加以分 析。整理了近场强震动台站附近建筑物的破坏机制, 尝试从地震动的角度对灾害现象加以诠释和解译。

\section{2. 发震断层与烈度分布}

鲁甸地震震区位于扬子准地台 (I 级) 凉山滇东台褶带 (II 级) 的滇东北台褶束 (III 级) 内, 区内发育北东向、近南北向和北西向多组断裂构造, 是大凉山次级活动块体的南部边界。震中区地质构 造复杂, 主体构造为北东向的段裂和褶皱, 其次为
北西向和南北向的断裂、褶皱。断裂构造主要有北 东向多条昭通-鲁甸断裂和北西向的包谷垴-小河 断裂, 该断裂呈左旋走滑性质 $[5,6]$ 。包谷垴-小河断 裂是与北东向的昭通-鲁甸断裂带相配套的次级断 裂, 走向 $\mathrm{N} 30^{\circ} \mathrm{W}$, 由数条断续展布的断层组成。 东南起于包谷垴以北的月亮山一带, 北西经龙头山、 乐红、小河、满天星, 止于东坪一带, 总长约 $40 \mathrm{~km}$ 。 沿断裂表现为断层垭口、断层槽地等断层地貌, 如 龙头山-翠屏一线沿断裂表现为较为平直的断层槽 地。翠屏村见断层露头剖面, 破碎带以断层角砾岩 为主, 断面擦痕清晰, 其侧伏角约 $30^{\circ}$, 指示断裂 具有走滑兼逆冲性质。

鲁甸地震出现了烈度IX度的高烈度极震区, VI 度区以上总面积约 10350 平方千米, 其中: IX度: 90 平方千米; VIII度: 290 平方千米; VII度: 1580 平方千米; VI度： 8390 平方千米[1]。地震烈度大 致呈粗圆形分布, 粨圆长轴方向与北西向的发震断 层走向基本一致。从烈度圈短轴方向来看, 西南方 向比北东方向的烈度衰减的要慢, 但不能排除北东 向构造参与的作用, 地震过程中可能存在一定量的 从北东向往西南方向破裂的震源破裂过程。地震烈 度的递减规律与地震动 PGA 衰减趋势也有很大的 相似性。

\section{3. 强震记录分析}

强震台站获得的三分量加速度时程记录一般 是由东西 (EW) 和南北 (NS) 2 个水平分量以及 1 个上下 (UD) 坚直分量来组成。冀昆、温瑞智、 等 ${ }^{[3]}$ 和崔建文、刘琼仙等 ${ }^{[4]}$ 研究了鲁甸地震 VI 度区 范围内 7 个强震台的峰值加速度 (PGA) 、峰值速 度 $(P G V)$ 在 $\mathrm{EW} 、 \mathrm{NS} 、 \mathrm{UD}$ 三个方向上的地震动 特性, 台站位置如图 1 所示。而鲁甸地震在IX度区 的震害调查表明, 房屋及建筑物的破坏在北东方向 具有一定的优势, 而在北西方向上也有一定的分布。

为了更好地体现地震动特性在平行于发震断 层方向和垂直于发震断层方向上的分布特征, 本文 将水平地震动重新分解、合成为平行断层分量和垂 直断层分量, 对 7 个强震台的记录进行转换, 并且 分别得到其平行于发震断层和垂直于发震断层的 PGA 如表 1 所示。

结合表 1 地震动平行断层方向分量、垂直断层 方向分量的 PGA 及图 1 中 7 个台站的地理位置分 布情况, 可以看出 PGA 分布特征与地震断层方向 
Risk Analysis and Crisis Response in Big Data Era (RAC-16)

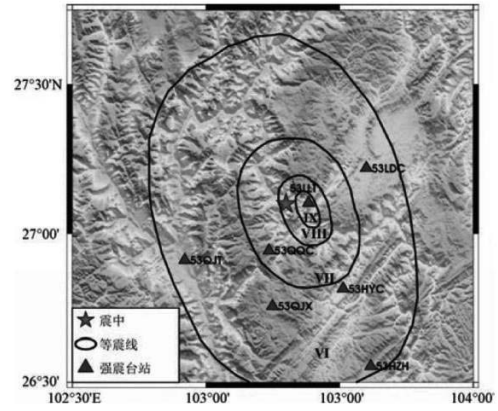

图 1 鲁甸地震VI IX 度区内强震动台站分布图

表 1 经过转换后的强震动记录相关参数

\begin{tabular}{|c|c|c|c|c|c|}
\hline \multirow[b]{2}{*}{$\begin{array}{l}\text { 台站 } \\
\text { 名称 }\end{array}$} & \multirow[b]{2}{*}{$\begin{array}{l}\text { 台站 } \\
\text { 代码 }\end{array}$} & \multirow[b]{2}{*}{ 场地 } & \multirow[b]{2}{*}{$\begin{array}{c}\text { 震中距 } \\
(\mathrm{km})\end{array}$} & \multicolumn{2}{|c|}{$\mathrm{PGA}\left(\mathrm{cm} / \mathrm{s}^{2}\right)$} \\
\hline & & & & $\begin{array}{l}\text { 平行 } \\
\text { 断层 } \\
\text { 方向 }\end{array}$ & $\begin{array}{l}\text { 垂直断 } \\
\text { 层方向 }\end{array}$ \\
\hline 龙头山 & 053LLT & 土层 & 4.38 & 699.5 & 1010.6 \\
\hline 铅厂 & 053QQC & 土层 & 20.23 & -143.0 & 137.6 \\
\hline 茨院 & 053LDC & 土层 & 29.07 & 48.5 & -42.7 \\
\hline 迤车 & 053HYC & 土层 & 36.00 & 98.1 & 85.9 \\
\hline 马树 & 053QJX & 土层 & 39.14 & -137.4 & 145.0 \\
\hline 巧家 & 053QJT & 基岩 & 46.43 & -18.9 & 25.5 \\
\hline 者海 & 053HZH & 土层 & 76.65 & 59.3 & 63.0 \\
\hline
\end{tabular}

相吻合, 震中位置及沿断层方向地震动新三分量的 PGA 比较大, 随着震源距的增加, PGA 由震源向 外延伸呈衰减趋势, 且延等震线长轴方向衰减的速 度要低于沿等震线短轴方向衰减的速度。

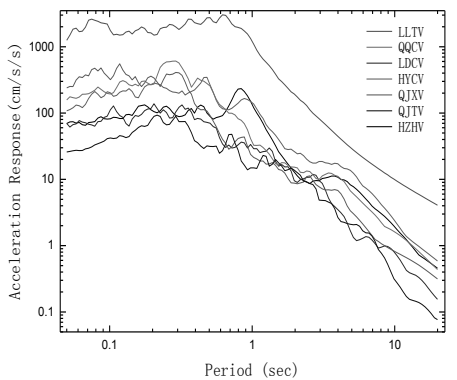

图 2 垂直断层分量的加速度反应谱

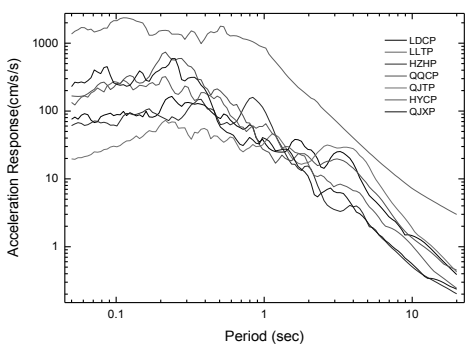

图 3 平行断层分量的加速度反应谱

从图 2 垂直断层分量的加速度反应谱来看, 龙头山 053LLT 台站的反应谱值最高, 其次 053QQC、053HYC、053QJX 这三个台站因为震中 距差别不是很大, 所以加速度反应谱的值比较接近, 在从低频到高频幅值有交叉区域。再远一点, 053HZH, 053QJT, 053LDC 这三个台站震中距相 近, 反应谱的振幅也差别不大。总体上, 还是遵循 一定的衰减规律, 即震中距越大反应谱振幅越小, VII 度区以上区域以及靠近 VII 的 VI 度区, 呈椭圆 形式向外扩散衰减, 长轴方向大致为北西方向。从 图 3 平行断层方向来看, 依然是 053LLT 台站是反 应谱振幅最大的区域。越靠近震源位置, 反应谱的 振幅越大。在垂直断层方向上, VII 度区以上区域 以及靠近 VII 的 VI 度区也同样是以椭圆形式向外 衰减。

\section{4. 灾害分析}

根据地震现场调查, 强震台站周围建筑物的 灾害严重程度与强震台所记录的地震动强度成正 比。

此次地震中最大的加速度峰值记录在震中距 $4.38 \mathrm{~km}$ 的龙头山镇台站 (台站代码 $053 \mathrm{LLT}$ ) 取得, 东西、北南和坚直方向的 PGA 分别为 $949 \mathrm{gal}$ 、 $-706 \mathrm{gal}$ 和 $-504 \mathrm{gal}$, 其中 $1000 \mathrm{gal}=10 \mathrm{~m} / \mathrm{s}^{2} \approx 1 \mathrm{~g}$ （重 力加速度）。龙头山强震台采用的是外置的国产 SLJ-100 型力平衡式加速度摆, 采集器为 ETNA, 如图 4、图 5 所示。 
Risk Analysis and Crisis Response in Big Data Era (RAC-16)

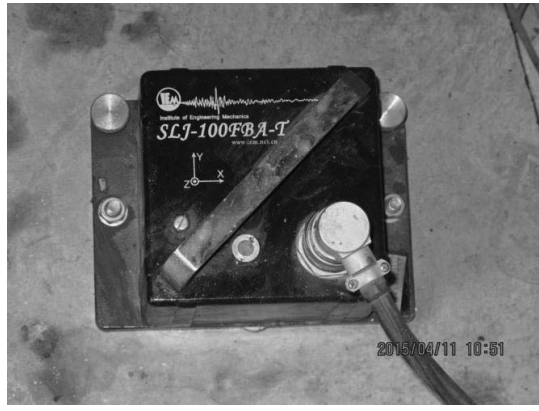

图 4 龙头山强震台 SLJ-100 型力平衡式加速度计

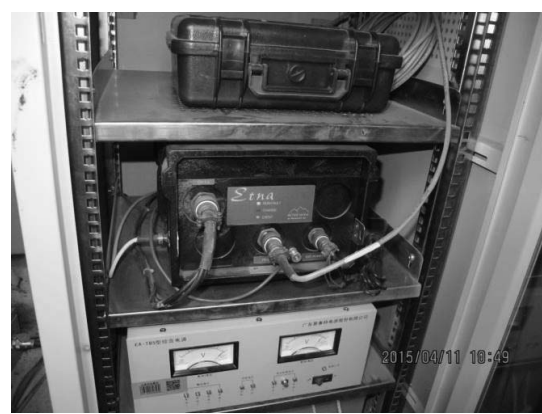

图 5 龙头山强震台 ETNA 数据采集系统

龙头山镇所在地为山脚河谷地带, 场地内海 拔高差大, 地貌复杂多变, 房屋基础多处于破碎松 散的堆积层上, 基础的整体性、稳定性和承重能力 差。加之超过一个 $\mathrm{g}$ 的强烈地震动作用, 使得龙头 山镇的房屋建筑倒塌严重, 地震烈度达到 IX 度, 如图 6 所示。

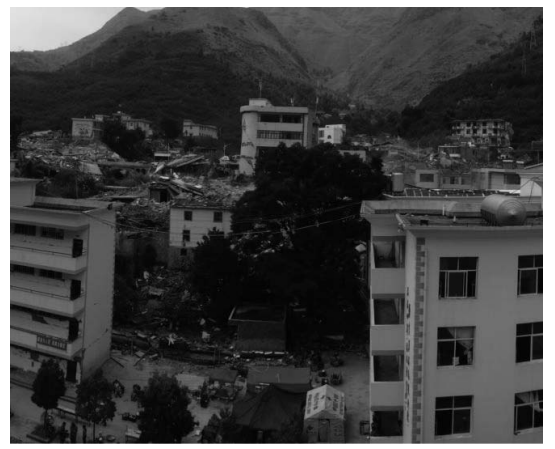

图 6 龙头山镇的场地地形及震后倒塌情况（镜头方向: 北西）
如图 7 所示, 将龙头山强震台的加速度记录 转换成平行断层方向与垂直断层方向。重新分解后 平行断层、垂直断层以及坚向三个分量的 PGA 分 别是 699.5gal、1010.6gal 和-504gal, 其中, 垂直于 断层方向 $\mathrm{N} 74^{\circ} \mathrm{E}$, 即北东向, 其峰值加速度 PGA 为 $1010.6 \mathrm{gal}$ 。分解后的加速度时程可以看出地震 动在该地区的卓越方向为 NE-SW (北东-西南) 方 向, 使得当地建筑在 NE-SW 方向上产生异常严重 的破坏。龙头山强震台周围建筑物的震害调查结果 恰好证明了这一点。如图 8、图 9 所示大量的建筑 物和工程结构的北东向墙体严重破坏。

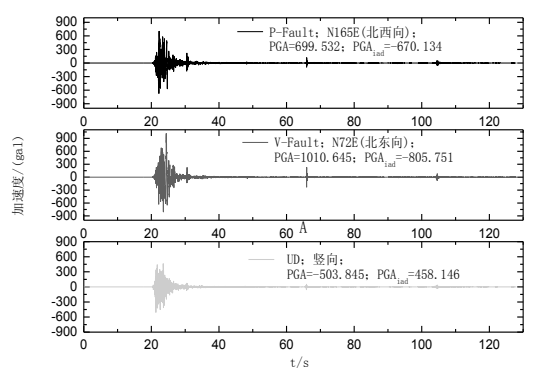

图 7 转换之后的 3 个方向龙头山加速度记录

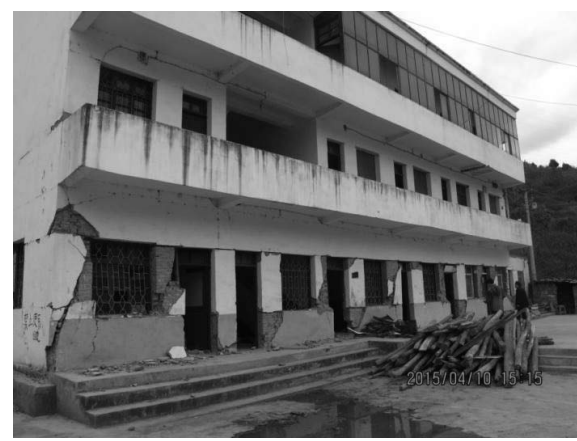

图 8 龙头山强震台附近三层砖混结构底层的剪切破坏 (镜头方向: 北东) 
Risk Analysis and Crisis Response in Big Data Era (RAC-16)

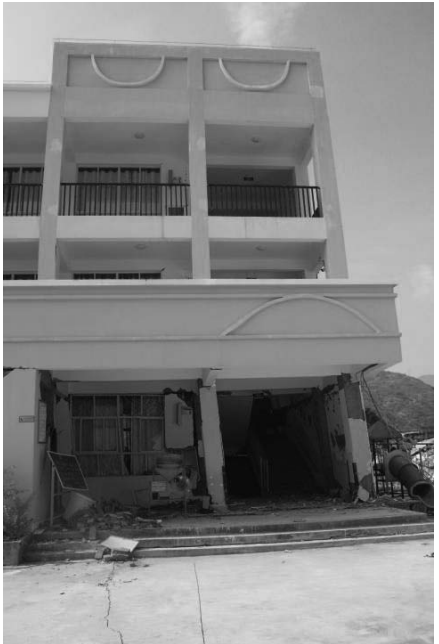

图 9 龙头山幼儿园三层框架教学楼向北东方向倾斜

在铅厂台站 (053QQC) 的新三分量 PGA 分 别为-143.0gal、137.6gal 和-52.8gal, 该台站震中距 仅比 $053 \mathrm{LLT}$ 远 $15.85 \mathrm{~km}$, 震源距远 $10.75 \mathrm{~km}$, 但 是 PGA 水平却显著低于 $053 \mathrm{LLT}$ 。此外, 震中距为 $39.14 \mathrm{~km}$ 的马树台站 (053QJX) 的水平分量 PGA 高达 137.4gal, 垂直断层分量达 145.0gal, 较震中 距少于 $39 \mathrm{~km}$ 的茨院台站 (053LDC) 与迤车台站 (053HYC) 要高出很多。现场调查和科学考察表 明：马树台站 (053QJX) 台站处于北侧高陡山边 台阶和西侧高边坡的交汇孤突部位（地形上）, 覆 盖土层 (红黏土) 厚 $18 \mathrm{~m}$, 北侧高陡台阶高出南侧 约 $15 \mathrm{~m}, 053 \mathrm{QJX}$ 台站距台阶边缘约 $15 \mathrm{~m}$, 东西方 向的边坡坡度约 $20^{\circ}$, 因此, 该台站处于孤突台地 上所具有的“凌空面放大效应”, 很可能是导致其强 震动记录的峰值加速度较高的原因。

生命线系统工程结构分为电力系统、交通系统、 通信系统、供排水系统及其他市政设施, 生命线工 程结构震害主要依据现场灾害调查汇总资料分析。 鲁甸地震是一次较典型的山区地震, 地震地质灾害 和强地震动共同作用是造成生命线工程破坏的主 要原因 ${ }^{[7]}$ 。通信系统在本次地震中受的影响相对较 小, 恢复也较快。交通系统的主要震害是山体滑坡 引起的道路中断, 灾区属于高山峡谷地形, 道路抢 通困难。电力系统的一些小型水力发电站破坏严重 （如图 10 所示）。另外, 龙头山变电站的破坏直 接导致其下级的 2 个变电站也断电, 体现着地震
灾害不仅对直接承灾体产生影响, 还以扩散方式传 导, 即通过直接承灾体对其它相关的承灾体产生影 响 ${ }^{[8]}$ 。

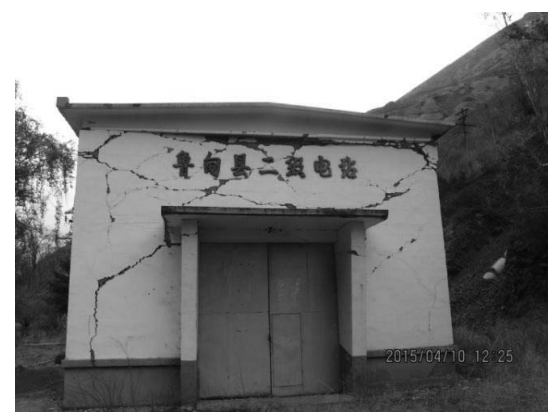

图 10 鲁甸二级电站墙体 X 型剪切裂缝

\section{5. 结论与讨论}

根据震级规模, 鲁甸地震仅为一次中强地震, 却造成了灾区大量人员伤亡 (617 人死亡、112 人 失踪) 和严重的财产损失（直接经济损失近 200 亿元人民币）。而同年 10 月 7 日发生的云南省景 谷地震, 震级略大于鲁甸地震, 仅造成 1 人死亡, 325 人受伤, 直接经济损约 51 亿元人民币, 为鲁 甸地震的 $1 / 4$ 。

本文作者在地震现场的震害调查基础上, 通过 对烈度VI度圈内的 7 个强震动台站记录的水平向 地震动, 沿平行于断层方向和垂直于断层方向分解、 合成为两组新的水平向地震动, 进一步分析了这两 组地震动的地震动峰值、频谱特性、衰减趋势及其 与建筑物、生命线工程的震害关系, 得到初步结论 如下:

1) 将极震区龙头山强震台获得的加速度记录重 新分解合成后, 在垂直于断层方向上的水平 向峰值加速度达到了 $1010.6 \mathrm{gal}$, 超过 1 个 g （重力加速度）。同时因为该场地为松散堆 积体, 因此造成建筑物破坏严重, 极震区烈 度达到IX度。其余 6 个台站的强震记录峰值 之间的大小关系表明, 地震动基本上呈椭圆 形向外衰减。

2) 震害调查表明, 地震地质灾害和强地震动作 用是造成生命线工程破坏的主要原因, 而高 山峡谷地形的山体滑坡导致的道路中断, 则 是交通系统的主要震害。交通系统的地震破 坏, 对震后抗震救灾造成了很大的影响。 
Risk Analysis and Crisis Response in Big Data Era (RAC-16)

3) 鲁甸地震再次表明, 对于经济相对落后的山 区容易发生“小震致灾，中震大灾”的现象。在 进行灾害风险评估时还应注意多灾种叠加效 应。

\section{Acknowledgements}

This study was supported by the Special Research Funding for the Public Institute of China, IGP, CEA (DQJB15C01), and National Natural Science Foundation of China (No.5127847).

\section{致谢}

本项研究受到中央级公益性科研院所基本业务专 项 (DQJB15C06) 和国家自然科学基金面上项目 (51278470) 的资助。

\section{参考文献}

[1] 卢永坤, 张建国等. 2014 年云南鲁甸 6.5 级地 震烈度分布与房屋震害特征, 地震研究, 37(4): 549-557,2014.

[2] 帅向华, 姜立新, 侯建盛等. 云南鲁甸 6.5 级
地震灾害特点浅析. 震灾防御技术, 9(3): 340-358, 2014

[3] 冀昆, 温瑞智, 崔建文等. 鲁甸 MS6.5 级地 震强震动记录及震害分析. 震灾防御技术, 9 (3) : 325-339, 2014.

[4] 崔建文, 刘琼仙等. 2014 年云南鲁甸 6.5 级地 震强震动观测记录及初步分析. 地震研究, 37 (4) : 542-548, 2014.

[5] 张勇, 陈运泰等. 2014 年云南鲁甸 MW6.1 地 震: 一次共轭破裂地震, 地球物理学报, 58(1): 153-162, 2014.

[6] 李西, 张建国等. 鲁甸 Ms6.5 地震地表破坏及 其构造的关系, 地震地质, 36 (4): 1280-1292, 2014.

[7] 刘爱文, 帅向华等. 鲁甸地震生命线工程震害 特点及应急抢修.震灾防御技术, 9(3): 359-367, 2014.

[8] Guo Shujun. The Meteorological Disaster Risk Assessment Based on the Diffusion Mechanism. Journal of Risk Analysis and Crisis Response, 2(2): 124-130, 2012. 